\title{
Power Congestion Control Considering UPFC to Enhance Voltage Stability of the System
}

\author{
S. Ravindra, U. P. Kumar Chaturvedula, M. Ravindra
}

\begin{abstract}
This paper proposes a new FACTS device, i.e., Unified Power Flow Controller (UPFC) to relieve power congestion on power grid network. A simple model of a three phase AC-network of $500 / 230 \mathrm{kV}$, 5-bus network with two transformers and two power generation plants (1000MW, $500 M W)$ is designed. UPFC is designed with IGBT converters connected in shunt- series and both interconnected with DC bus and connected to AC side with transformer and coupling reactors. A contingency case is considered such that two transformers are considered instead of three transformers. The power flow of an UPFC installed at Bus-3 in 5-bus system is analyzed to show how the congestion of power on the grid is relieved through it. A bypass circuit breaker is installed at Bus -3 in the circuit to show the natural power flow without UPFC and power flow after installation of UPFC. The topology of series converter build in UPFC can introduce maximum of $10 \%$ of line-ground voltage in series. The simulation network of the 5-bus transmission network with UPFC connected at Bus-3 is designed with MATLAB/SIMULATION Software to estimate the power flow with UPFC connected.
\end{abstract} UPFC.

\section{INTRODUCTION}

Due to heavy load demand, the transmission lines are forced to operate at maximum limits. This causes many congestion problems in deregulated power system. The capability of transmission network to transfer power depends up on various factors such as voltage limits, stability limits and thermal limits. If any violation of the limits may lead congestion problems and loses the security of the network, so the operator of the system should consider the system not being under violation condition. Congestion problem in system results in increase of cost of the power which is not economically satisfactory. The UPFC is the one of most

Revised Manuscript Received on February 13, 2020.

* Correspondence Author

S. Ravindra, Department of Electrical and Electronics Engineering, Vasireddy Venkatadri Institute of Technology, Numbur, Guntur, India. Email:sanguravindra11@gmail.com

U. P. Kumar Chaturvedula, Department of Electrical and Electronics Engineering, Aditya College of Engineering, ADB Road, Surampalem, A.P, India. Email: contactchathurvedula@gmail.com

M. Ravindra*, Department of Electrical and Electronics Engineering, Aditya College of Engineering, ADB Road, Surampalem, A.P, India. Email: ravieeejntu@gmail.com

(C) The Authors. Published by Blue Eyes Intelligence Engineering and Sciences Publication (BEIESP). This is an open access article under the CC BY-NC-ND license (http://creativecommons.org/licenses/by-nc-nd/4.0/)
Keywords : Congestion, FACTS, Power Flow, Power Grid,

powerful Facts device, introduced by Gyugyi [1]-[3].Various mathematical model of UPFC has been introduced depends upon various purpose of application. UPFC is studied for application of congestion management in power system. With implementation of FACTS devices, using series compensation there is an improvement of loadability in transmission lines [4]-[6]. There several methods adopted for congestion management in power system such as Generator Rescheduling (GR) method, Distribution Generation (DG) method, cost free methods, nodal pricing methods, and load shedding methods. The reviews of the methods are shown in [7]. Author in [8] presented a novel technique for congestion management in 5-bus network by controlling the active power flow using TCSC and author considered sensitive analysis for location of TCSC device. The author in [9] presented the rescheduling of generators to control active power with congestion management simultaneously reducing the cost of rescheduling. To minimize the rescheduling cost the method used is TLBO method. A decomposition algorithm is proposed to mitigate and predict the congestion problems in power system network under renewable load uncertainty [10]. An improved strategy of multi-objective computation techniques have been proposed in [11] for congestion management. Dynamic crowding distance is also proposed in the method in order to maintain diversity among non dominated solutions. The author in [12] presented a multi-agent system based congestion management. In this process control of active power is realized based on active power distribution factor. The author in [13] presented the effect of UPFC device in the power system. One of the problems that exist in an integrated power system environment is congestion problem between buses due to insufficient generation and transmission or inadequate transformers there is uneven distribution of power. UPFC when placed on tie lines connecting two areas should be able to rectify the congestion problem with control the active and reactive power uniformly. Since UPFC is a multi-variable controller, it should be able to improve power system stability under dynamic conditions. In this paper congestion problem occurs in transmitting the power using two transformers instead of three. This congestion problem is studied considering 5-bus network and using of Facts device such as UPFC at the bus with congestion problem. Remaining of this paper is organized as: section II presents the modeling of UPFC for congestion management; section III describes the SIMULINK model of UPFC for congestion problem, section IV deals with the results and discussion and section $\mathrm{V}$ concludes problem. 


\section{Power Congestion Control Considering UPFC to Enhance Voltage Stability of the System}

\section{MODELING OF UPFC FOR CONGESTION MANAGEMENT}

\section{A. Basic Principle of UPFC}

UPFC comprises of two VSC linked mutually with a dc 3link. To provide electrical isolation and to match line and inverter voltages, two transformers are necessary. One of the transformers is coupled in series with line and other is coupled in parallel with the line. The main purpose of UPFC is to not only manage the power flow on a specified transmission line but also to maintain constant bus voltage at point of common coupling (PCC).
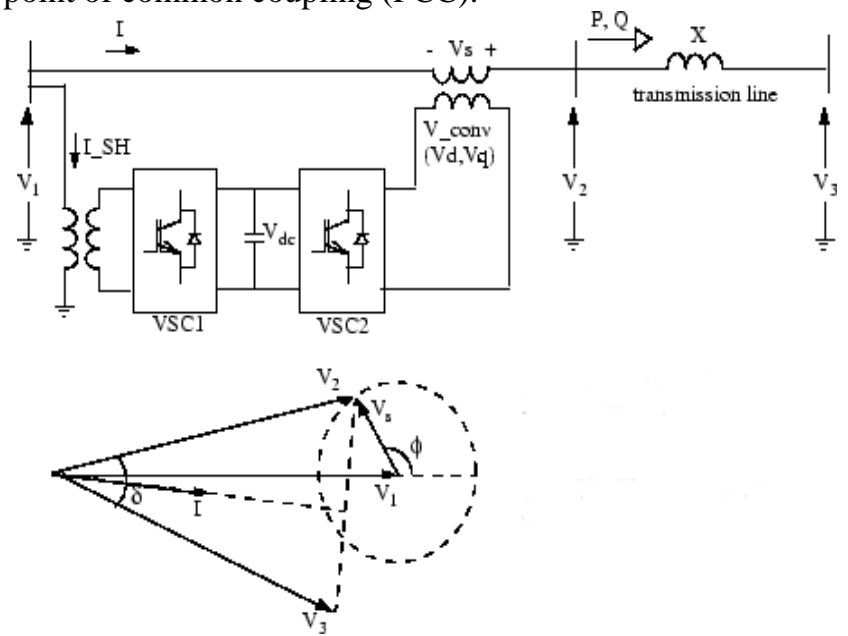

Fig.1.Single Line diagram of UPFC and Phasor diagram

This can be accomplished by injecting a controlled voltage in series with line voltage. The magnitude and phase angle of newly introduced voltage can be transformed instantaneously or distinctly. The series connected converter turns as controllable voltage source and the shunt connected converter turns as controllable current source as shown in fig 1.

The converter i.e., coupled in series can produce a voltage which is adjustable. The real and reactive power can be altered by controlling voltage injection in series. The real power required by series converter is provided or engaged by shunt converter through dc link. Shunt converter can consume or supply reactive power simultaneously. The UPFC regulates all 3 parameters that change power flow in network. Fig. 3 presents simplified UPFC with two voltage sources $V_{\text {se }}$ and $V_{\text {sh }}$ which is controllable in magnitude and phase angle and with appropriate impedances. $x_{s e}$ is reactance of UPFC which is considered from transmission line side of series transformer. The UPFC voltage sources are:

$$
\begin{aligned}
& \overline{V_{s e}}=V_{s}\left(\cos \varphi_{s}+j \sin \varphi_{s}\right) \\
& \overline{V_{s h}}=V_{h}\left(\cos \varphi_{h}+j \sin \varphi_{h}\right)
\end{aligned}
$$

Where $V_{s}$ series voltage is source magnitude, and $\varphi_{s}$ is series voltage source angle and $V_{h}$ is shunt voltage source magnitude, and $\varphi_{h}$ is shunt voltage source angle. The obtained voltage output $V_{s}$ determines VR and phase angle $\varphi_{s}$ provides mode of UPFC.

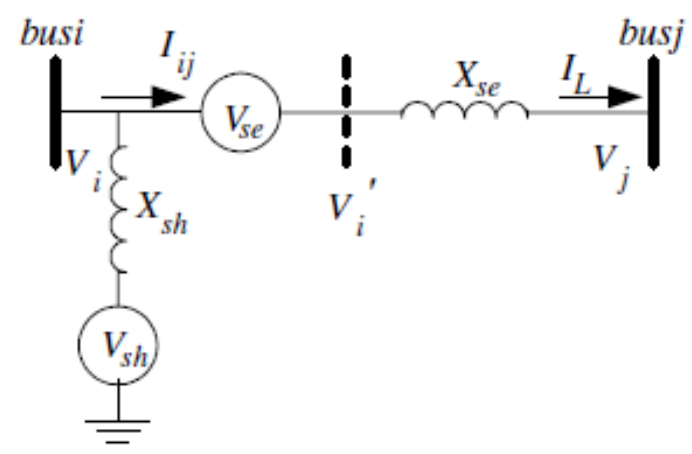

Fig.2. Single Line diagram of UPFC

$$
\begin{aligned}
& P_{i}=V_{i}^{2} G_{i i}+V_{i} V_{j}\left(G_{i j} \cos \left(\varphi_{i}-\varphi_{j}\right)+B_{i j} \sin \left(\varphi_{i}-\varphi_{j}\right)\right) \\
& +V_{i} V_{s e}\left(G_{i j} \cos \left(\varphi_{i}-\varphi_{s e}\right)+B_{i j} \sin \left(\varphi_{i}-\varphi_{s e}\right)\right) \\
& +V_{i} V_{s h}\left(G_{s h} \cos \left(\varphi_{i}-\varphi_{s h}\right)+B_{s h} \sin \left(\varphi_{i}-\varphi_{s h}\right)\right. \\
& Q_{i}=-V_{i}^{2} B_{i i}+V_{i} V_{j}\left(G_{i j} \sin \left(\varphi_{i}-\varphi_{j}\right)-B_{i j} \cos \left(\varphi_{i}-\varphi_{j}\right)\right) \\
& +V_{i} V_{s e}\left(G_{i j} \sin \left(\varphi_{i}-\varphi_{s e}\right)-B_{i j} \cos \left(\varphi_{i}-\varphi_{s e}\right)\right) \\
& +V_{i} V_{s h}\left(G_{s h} \sin \left(\varphi_{i}-\varphi_{s h}\right)-B_{s h} \cos \left(\varphi_{i}-\varphi_{s h}\right)\right.
\end{aligned}
$$

This UPFC designed provides more flexibility for controlling active and reactive power compared to SSSC because power is transferred through DC bus from shunt converter to series converter. Contrary to SSSC where injected voltage $V_{s}$ is controlled to reside in quadrature along with line current I, we can observe that injected voltage $V_{s}$ has any angle with current. If voltage magnitude $V_{s}$ is considered constant and if phase angle $\varphi$ is changed from 0 degrees to 360 degrees with respect to $V_{1}$ the locus determined by vector $V_{2},\left(V_{2}=V_{1}+V_{s}\right)$ is a circle as presented on phasor diagram.

As phase angle varies, there is phase shift between $V_{2}$ and

\begin{tabular}{|c|c|}
\hline Reactance & $0.35 \Omega / \mathrm{km}$ \\
\hline Line length & $200 \mathrm{~km}$ \\
\hline Voltage & $500 \mathrm{kv}$ \\
\hline$V_{1}$ & 1.p.u, Odegrees \\
\hline$V_{3}$ & 1.p.u, -7.22 degrees \\
\hline $\begin{array}{c}\text { Rating of Series and shunt } \\
\text { converter (UPFC }\end{array}$ & 100MVA \\
\hline $\begin{array}{c}\text { series converter injected } \\
\text { voltage }\end{array}$ & $\begin{array}{c}10 \% \text { of } 28.9 \mathrm{kv} \text { (line to ground } \\
\text { voltage) }\end{array}$ \\
\hline $\begin{array}{l}\text { Transformer impedance, } \\
\text { leakage reactance, filters. }\end{array}$ & 0.15p.u \\
\hline
\end{tabular}
$V_{3}$ and follows active power and reactive power injected at one end can be regulated. The controllable region P-q plane is area in form of ellipse, as shown on fig. 3.

This plot was designed with parameters of transmission line of 100 MVA UPFC installed at one end regulating active and reactive power. The parameters are shown in Table I.

Table I. Parameters 


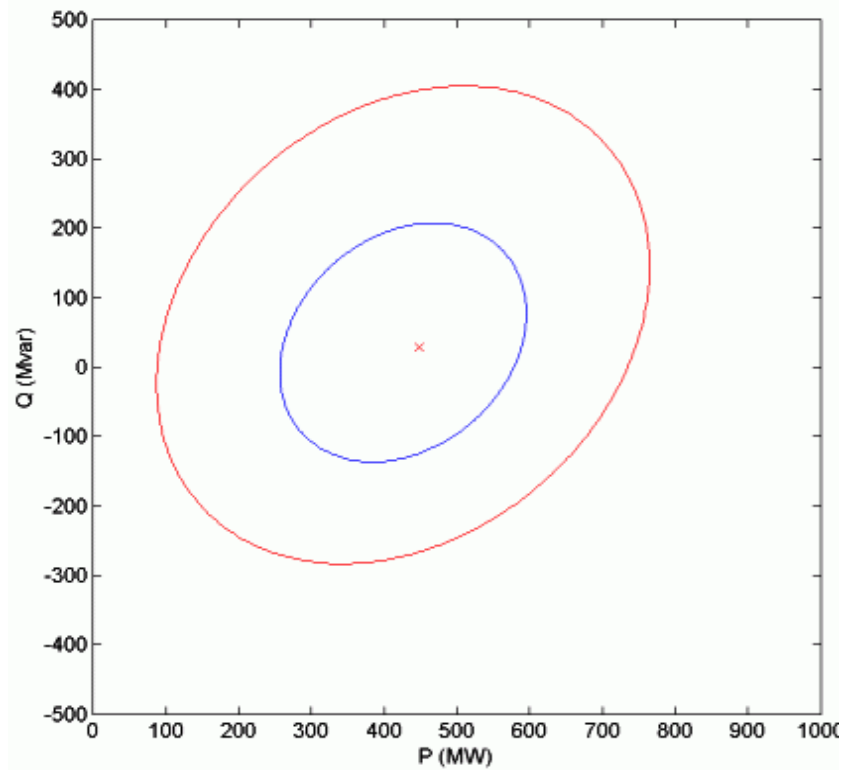

Fig. 3. Controllable Region of UPFC Connected

Without compensation, the power flow is $450 \mathrm{MW}$ with $V_{3}$ lags $V_{1}$ by 7.21 degrees. Operating point (OP) inside ellipse is found with injected voltage $V_{s}=0.1 p$.u and active power is assorted by approximately $300 \mathrm{MW}$.

Shunt converter in UPFC acts as STATCOM which regulates voltage $V_{1}$ by consuming or developing reactive power. UPFC combined with series and shunt use a VSC device connected on secondary part of coupling transformer. The capacitor associated on DC part of VSC operates as DC voltage source. Special inter connected transformers are utilized to reduce the effect harmonics enclosed in square waves produced by inverters. In this, the fundamental voltage is relative to $V_{d c}$ voltage i.e., proportional to $V_{d c}$. Therefore, to vary $V_{d c}$ injected voltage has to be regulated.

The VSC considering IGBTs uses PWM technique to create sinusoidal waveforms from DC voltage with a distinctive chopping frequency $(\mathrm{KHz})$. Harmonics are eliminated by utilizing filters at AC part of VSC. This VSC considers preset DC voltage $V_{d c}$. Voltage is deviated by altering modulation index of PWM modulator.

In this model of UPFC design, IGBT can be used GTO for transient stability studies as harmonic are not considered here.

\section{SIMULATION MODEL OF UPFC FOR CONGESTION PROBLEM}

Simulink model of UPFC phasor is designed with integrated STATCOM (Shunt controller) and SSSC (series controller) blocks of MATLAB. Simulink schematic diagram of UPFC is presented in Fig.4. Simulink diagram of series and shunt controllers are shown in Fig. 5 and 6.

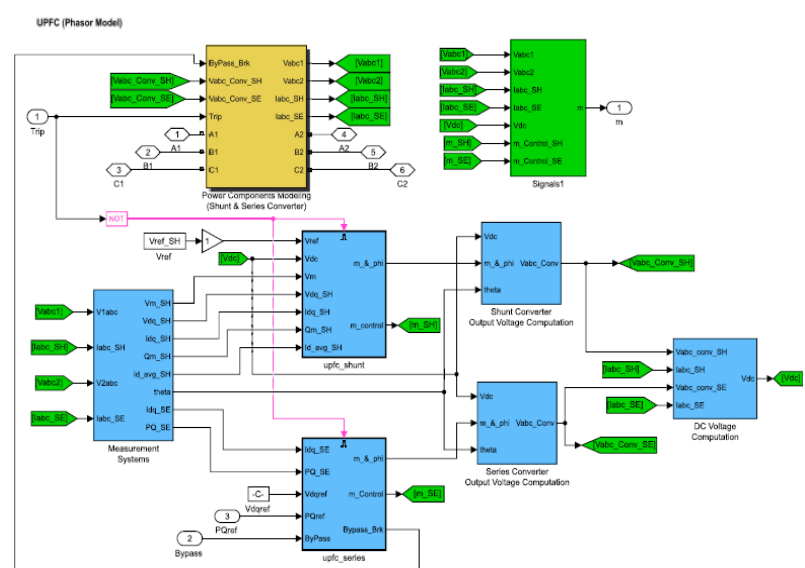

Fig.4. Simplified block diagram of UPFC

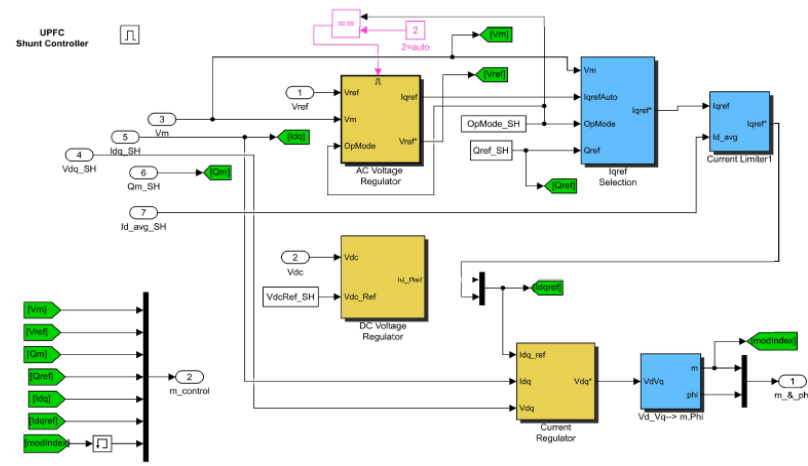

Fig.5. Simplified block diagram of UPFC shunt controller

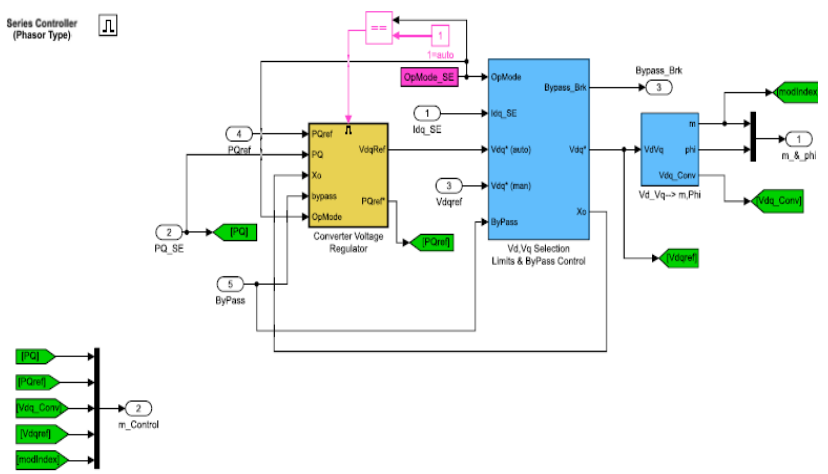

Fig. 6. Simplified block diagram of UPFC series controller

D-Q model of 3-phase series R-L:

$$
\begin{aligned}
& V_{d 1}-V_{d 2}=\left[R I_{d}\right]-\left[L W I_{q}\right]+\left[L d I / d t\left(I_{d}\right)\right] \\
& V_{q 1}-V_{q 2}=\left[R I_{q}\right]-\left[L W I_{d}\right]+\left[L d I / d t\left(I_{q}\right)\right]
\end{aligned}
$$

Where $W=2 p i(H Z)$ utilizing Laplace transform and per unit quantities

$$
\begin{aligned}
& I_{d}=[W /(L S)] *\left[V_{d 1}-V_{d 2}-\left(R^{*} I_{d}\right)+\left(L I_{q}\right)\right] \\
& I_{q}=[W /(L S)] *\left[V_{q 1}-V_{q 2}-\left(R * I_{q}\right)+\left(L I_{d}\right)\right]
\end{aligned}
$$

Fig 10. shows d-q axis model of 3-phase series R-L circuit designed for UPFC. 
Power Congestion Control Considering UPFC to Enhance Voltage Stability of the System

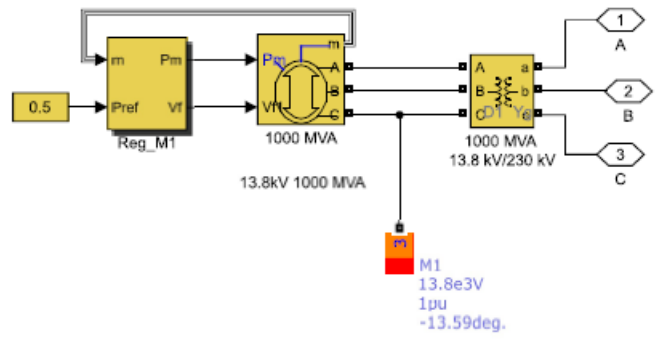

Fig.7. Simplified Block Diagram Plant1

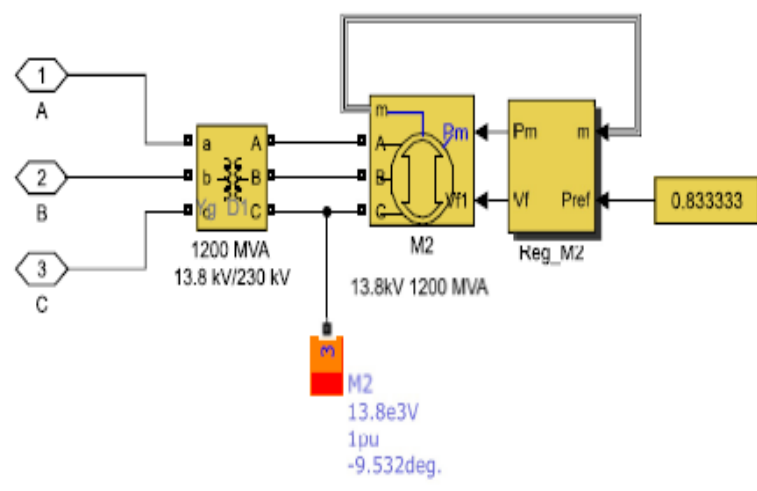

Fig.8. Simplified Block Diagram Plant2

Fig. 7 and 8 demonstrates the designed generation blocks of plant 1 and plant 2

\section{RESULTS AND ANALYSIS}

This paper is simulated in MATLAB SIMULINK environment which is run on Intel(R) core(TM), i3 processor at $2.20 \mathrm{GHz}, 4 \mathrm{~GB}$ of RAM. Various blocks are considered to design the UPFC which were briefly described.

The connected system in loop configuration, designed with five buses $B 1$ to $B 5$ connected via transmission lines $(L 1, L 2, L 3)$ and two transformers $(\operatorname{Tr} 1$ and $\operatorname{Tr} 2)$. Two plants situated on $230-\mathrm{kV}$ system produce a total of 1500 MW which is send to 500-kV 15000-MVA and to bus B3 200-MW load connected. In general operation, plant 2 generation i.e., 1200-MW capacity is transmitted through three 400-MVA transformers to buses B4 and B5 equivalent to $500 \mathrm{kv}$.

A contingency case is considered in which two transformers are available out of three transformers required.

From the load flows, it can be observed that, the power (899 out of $1000 \mathrm{MW}$ ) produced by plant 2 is transmitted by 800-MVA transformer and remaining power is circulated in the loop. Thus transformer 2 is overload by 99MVA. The problem is how UPFC relieves this congestion. The UPFC allocated at Bus-3 of line L2 is used to regulate active and reactive powers at $500-\mathrm{kV}$ bus $\mathrm{B} 3$, as well as voltage at bus B3. Parameters of the UPFC power components are given in Table II.

The references of $\mathrm{P}$ and $\mathrm{Q}$ are set as $P_{\text {ref }}$ and $Q_{\text {ref }}$. Generally when Bypass breaker is closed the active and reactive power flow at bus B3 is $587 \mathrm{MW}$ and $-27 \mathrm{Mvar}$. The $P_{\text {ref }}$ block is plotted with preset active power of 5.87 p.u parallel to general power flow.
Table II Parameters of UPFC Component

\begin{tabular}{|c|c|}
\hline System parameters & Value \\
\hline UPFC & 100MVA \\
\hline Line L1 & $\begin{array}{c}\text { Double Circuit, } \\
\text { 230KV,65Km }\end{array}$ \\
\hline Line L2 & $50 \mathrm{Km}, 500 \mathrm{KV}$ \\
\hline Line L3 & $50 \mathrm{Km}, 500 \mathrm{KV}$ \\
\hline Transformer banks T1 & 1000MVA,500KV/230K \\
\hline Transformer banks T2
\end{tabular}

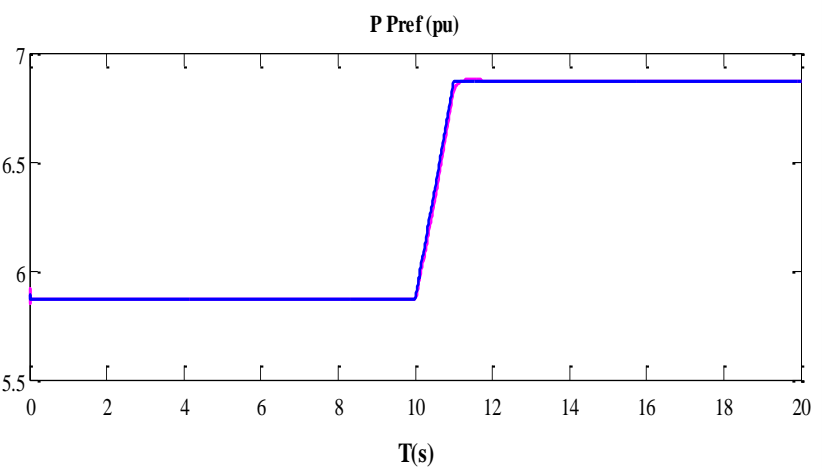

Fig.11. Active power and reference active power

. From the Fig. 11, 12 and 13 it is observed that, at $\mathrm{t}=10 \mathrm{~s}$, $P_{\text {ref }}$ is increased by $1 \mathrm{pu}(100 \mathrm{MW})$, from $5.87 \mathrm{pu}$ to $6.87 \mathrm{pu}$, while $Q_{\text {ref }}$ is kept constant at $-0.27 \mathrm{pu}$.

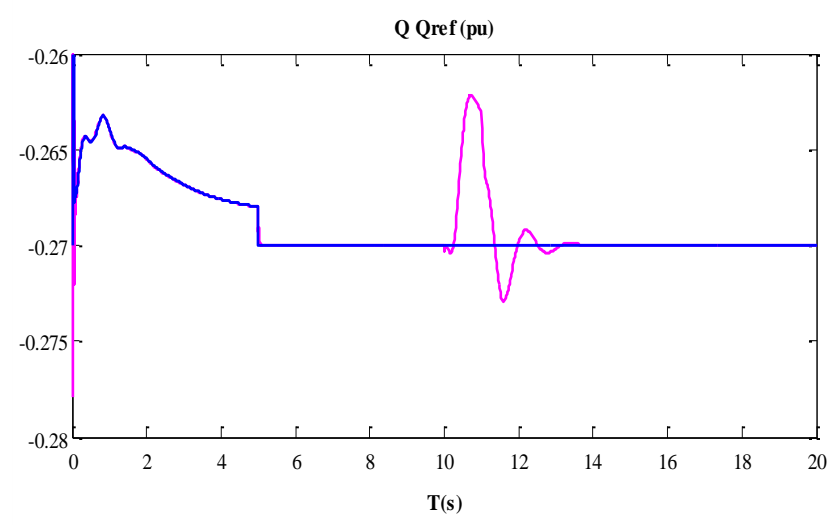

Fig. 12. Reactive power and reference reactive power

From the simulation results of P and Q considered at Bus-3 pursue reference values. When bypass breaker is opened at $\mathrm{t}=5 \mathrm{~s}$, the general power is sidetracked from UPFC without visible transient. 


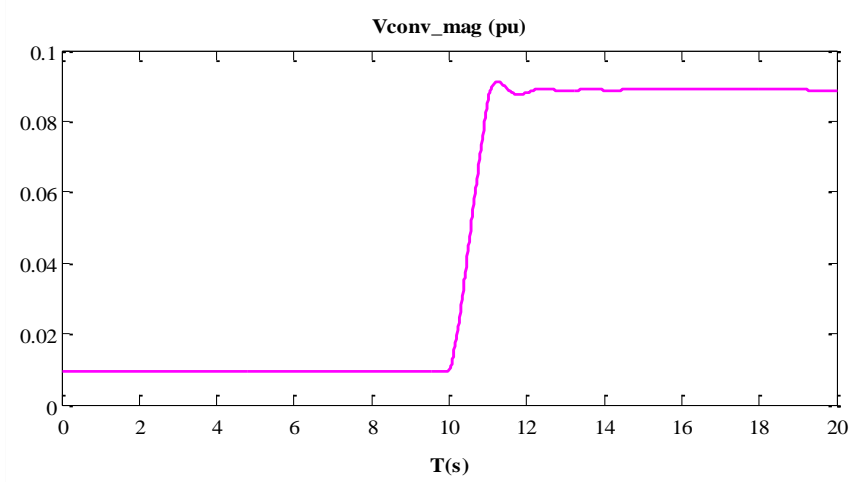

Fig.13 Series Injected voltage by series controller in UPFC

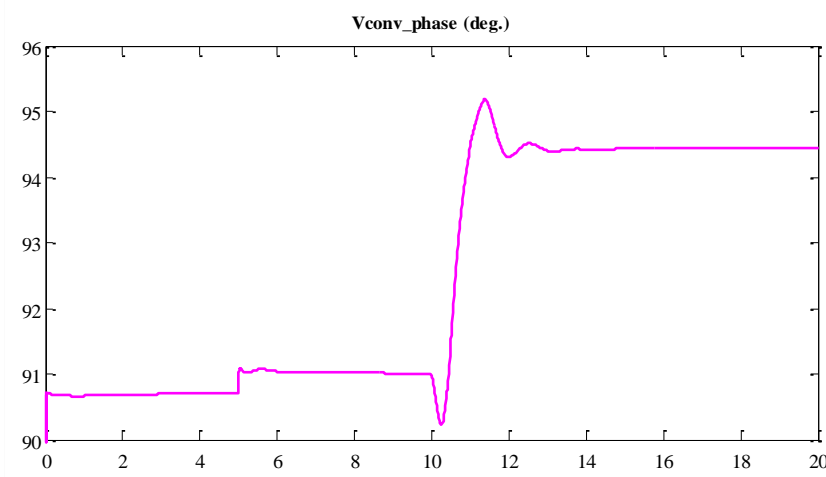

Fig. 14. Phase of Injected series Injected voltage

The magnitude and phase angle of injected voltage are presented in Fig. 13 and 14. When breaker opens, magnitude of injected series voltage is increased, from 0.00945 to 0.1 pu. and phase angle is increased from 90.8 degrees to 95 degrees.

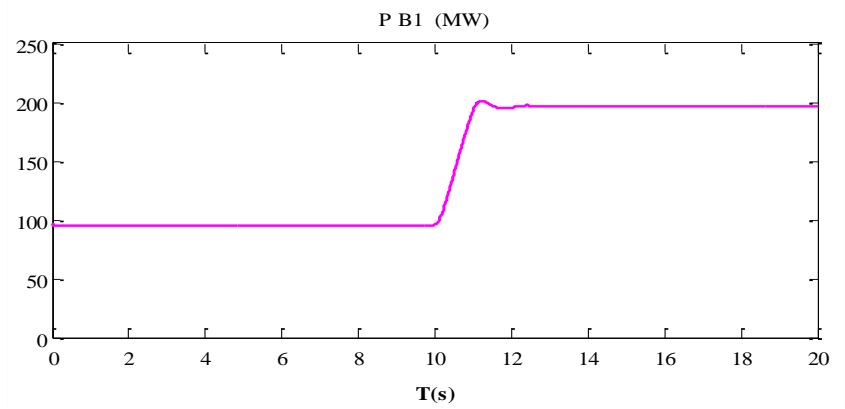

Fig. 15. Active Power Measured at Bus-1

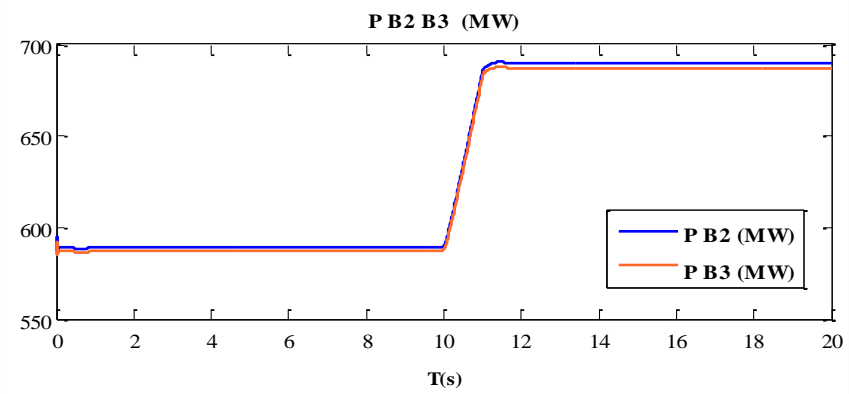

Fig.16. Active power measured at Bus-2 and 3

From Fig. 15 and 16 , it is observed that power at $\mathrm{t}=10 \mathrm{sec}$, active power at bus-1 increases from 95MW to 197MW, and at bus-2 increases from 589MW to 690MW and at Bus -3 , increases from 587MW to 687MW. It nearly take one second for change in power.

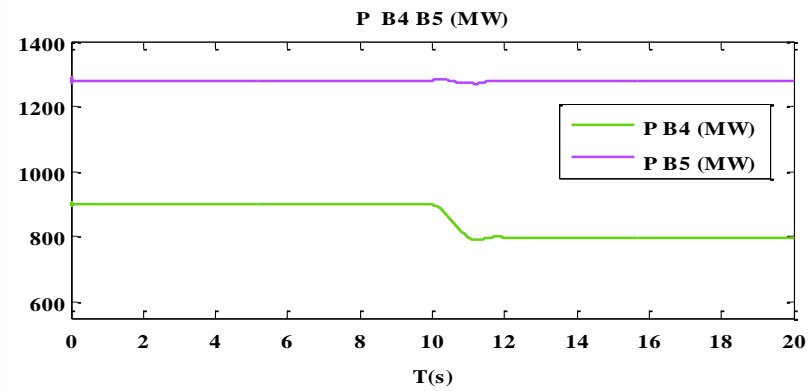

Fig 17. Active Power Measured at Bus-4 and 5

From Fig. 17, it is observed that at $\mathrm{t}=10 \mathrm{sec}$, active power at bus-4 decrease from $899 \mathrm{MW}$ to $796 \mathrm{MW}$, and at bus-5 power decreases from $1279 \mathrm{MW}$ to $1277 \mathrm{MW}$. From figure 16 and 17 , it can be observed that at $\mathrm{t}=10 \mathrm{~s}$, power increases at a rate of $1 \mathrm{pu} / \mathrm{s}$. It takes $1 \mathrm{~s}$ to increase power to $686 \mathrm{MW}$. This is attained at bus-3 by injection of series voltage $0.0889 \mathrm{pu}$ ) with an angle of 94 degrees. In result, there is decrease of 100 MW of active power transmitted through Tr2 (from 898 MW to $797 \mathrm{MW}$ ), which now transmits an adequate load.

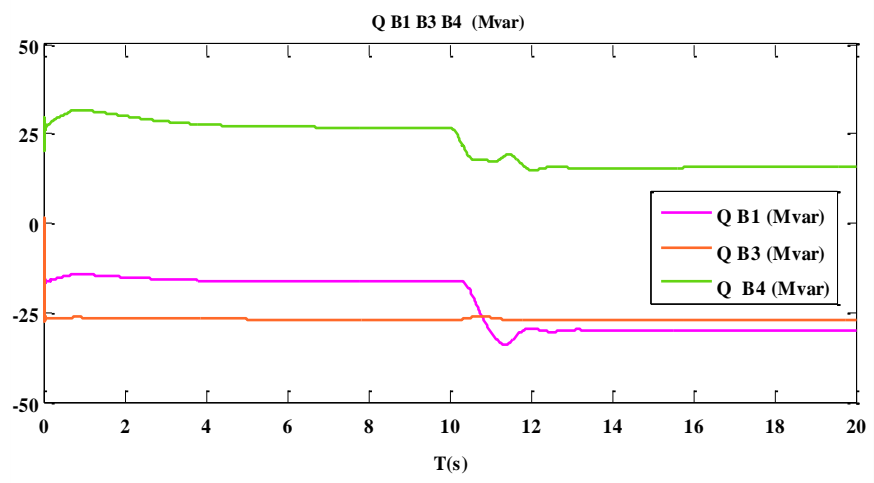

Fig. 18. Reactive power measured at Bus-1,3 and 5

From figure 18, it can be observed that at bus-3, the reactive power $-27 \mathrm{MW}$, is maintained constant throught with UPFC installed at bus -3 . At $\mathrm{t}=10 \mathrm{sec}$ Reactive power decreases for B1 and for B4 from 28Mvar to15Mvar.

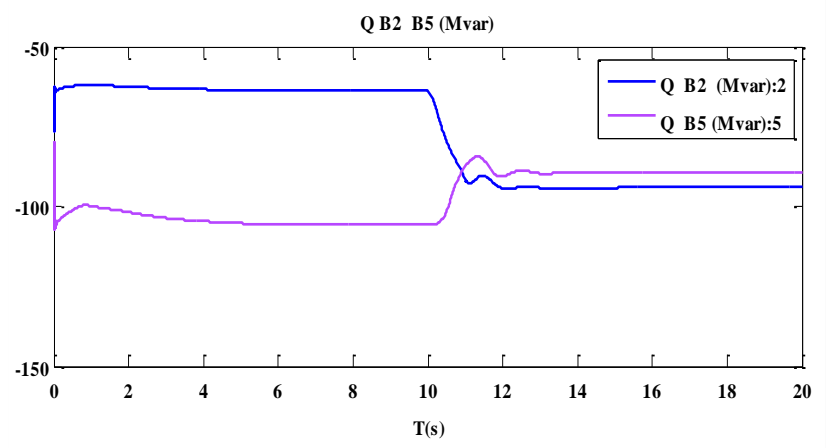

Fig. 19. Reactive power measured at Bus-2, and 5.

From Fig 19, it can be observed that at $\mathrm{t}=10 \mathrm{sec}$, for bus-5, reactive power increases and for bus-2, reactive power decreases.

Published By:

Retrieval Number: C5802029320/2020@BEIESP

DOI: 10.35940/ijeat.C5802.029320

Blue Eyes Intelligence Engineering \& Sciences Publication 


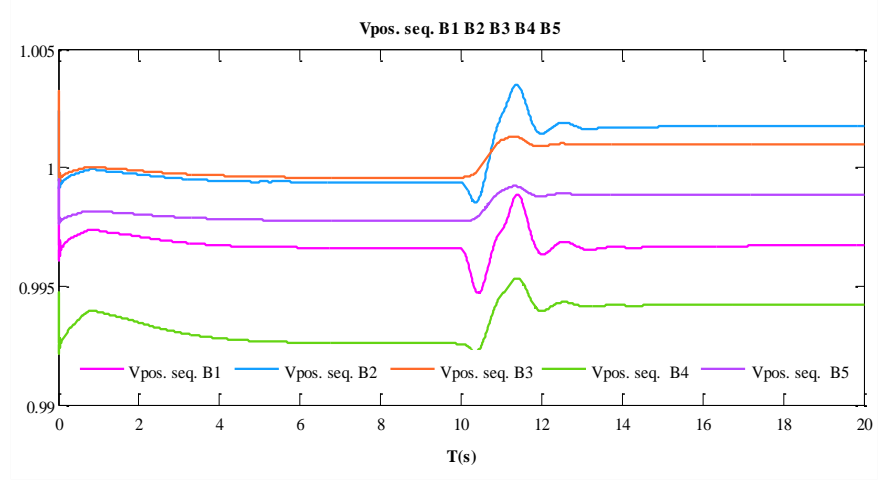

Fig. 20. Positive sequence voltages of Bus -1,2,3,4,and5

From fig. 20, it can be observed that, from $\mathrm{t}=10 \mathrm{sec}$ positive voltage sequence voltage lies between 0.95 p.u to 1.05 p.u., which is under stability constraints.

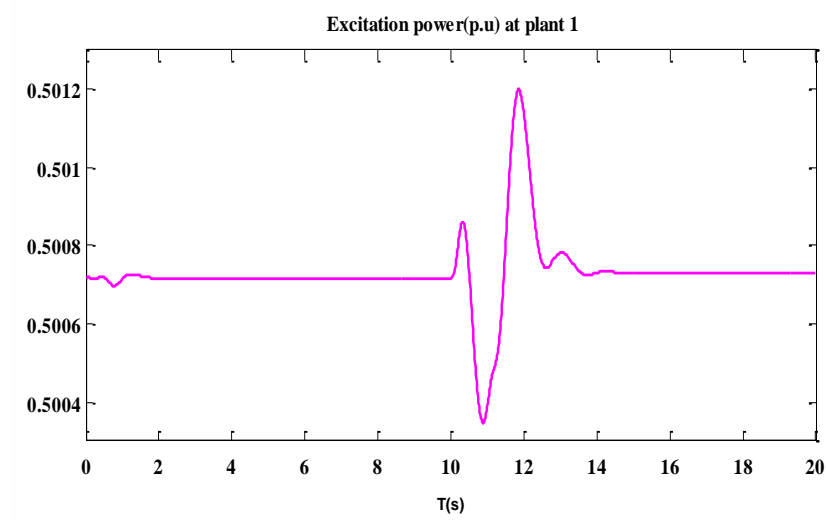

Fig. 21. Excitation power of plant 1

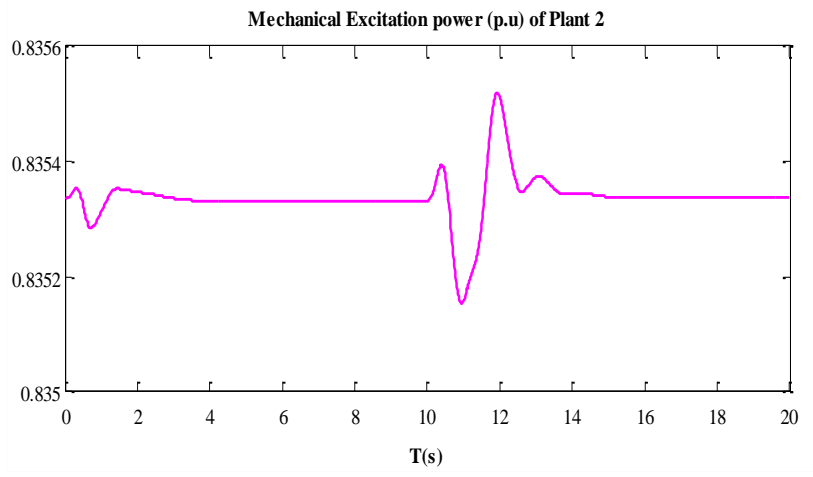

Fig 22. Excitation power of plant 2

From Fig. 21 and 22, it can be observed that transients appear at initial 0 to 2 seconds and 10 to $14 \mathrm{sec}$ when switch is opened or closed. Similar behavior absorbed in Fig. 23 and 24., for excitation of voltages in plant 1 and plant2.

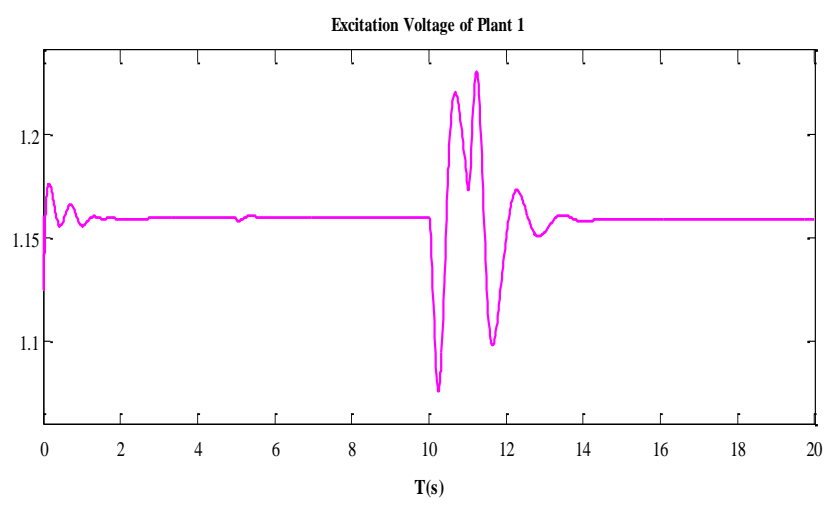

Fig. 23. Excitation voltage of plant 1

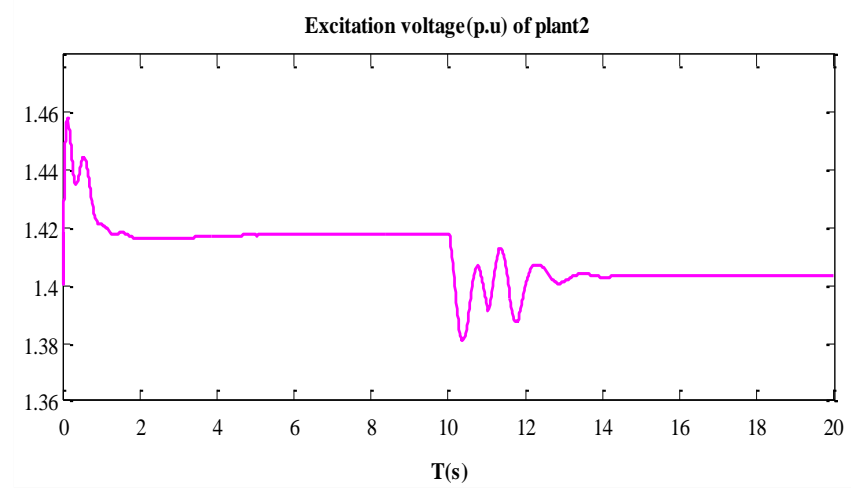

Fig.24 Excitation voltage of plant 2

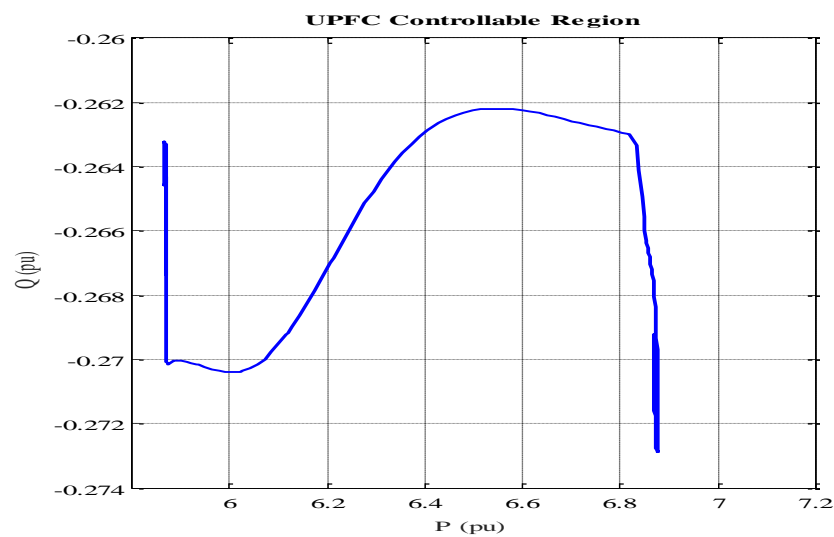

Fig. 25. Controllable region of UPFC

The controllable region of UPFC i.e., the trajectory of UPFC is presented in Fig 25. The reactive power measured at bus 3 which operates as function of active power is demonstrated. For first five seconds the PQ trajectory stays at the -27Mvar, 587 MW point (bypass breaker stays closed).

\section{CONCLUSION}

This paper presented, how the congestion problem is relieved utilizing UPFC in a 5-bus network. The active and reactive power flow of all the buses is shown with and without UPFC. The simulation network of 5-bus network with UPFC located at bus-3 is designed to show how the congestion problem is solved. The UPFC integrated in network to organize power flow in particular buses and lines and to enhance protection of network lines. Active and reactive power flows at each bus and excitation voltages at plants are presented to show how effectively the UPFC works. This work describes the effect of UPFC to enhance dynamic stability reducing congestion problems in power systems. Different simulations are computed in MATLAB SIMULINK environment.

\section{REFERENCES}

1. Gyugyi, L, "A Unified Power Flow Control Concept for Flexible AC Transmission Systems," IEE Proceedings-C, Volume-139, No.4, (July 1992).

2. L. Gyugyi, C.D. Schauder, S.L. Williams, T.R.Rietman, D.R Torgerson, A. Edris, "The Unified Power Flow Controller: A New Approach to Power Transmission Control, "IEEE Trans., Vol. PWRD-10,No. 2, pp. 1085-1097, April 1995.

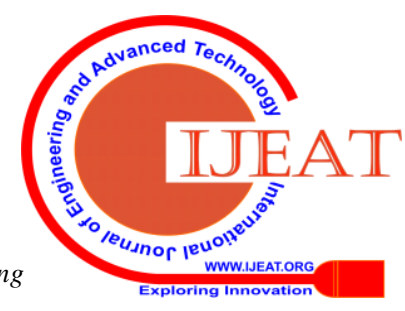


3. Kalyan K. Sen, and Eric J. Stacey, "UPFC - Unified Power Flow Controller: Theory, Modeling and Applications", IEEE Trans. on Power Delivery, 13 (4) (1998), p. 1453.

4. L.Rajalakshmi, M.V.Suganyadevi, and S.Parameswari "Congestion Management in Deregulated Power System by Locating Series FACTS Devices", International Journal of Computer Applications (0975 8887) Volume 13- No.8, January 2011.

5. Narain.G.Hingroni,Laszlo Gyugyi, "Understanding FACTS", $11^{\text {th }}$ Edition Wiley, New Delhi, 2013, pp. 209-210.

6. N. Kirthika and Balamurugan. S, "A new dynamic control strategy for power transmission congestion management using series compensation", Elsevier - International Journal of Electrical Power and Energy Systems,vol. 77, pp. 271 - 279, 2016.

7. Yusoff, N.I., Zin, A.A.M. and Khairuddin, A.B., 2017, April. Congestion management in power system: A review. In Power Generation Systems and Renewable Energy Technologies (PGSRET), 2017 3rd International Conference on (pp. 22-27). IEEE.

8. Surya, R., Janarthanan, N. and Balamurugan, S., ANovel Technique for Congestion Management in Transmission System by Real Power Flow Control.

9. Bhattacharya, S., Kuanr, B.R., Routray, A. and Dash, A., 2017, April. Transmission congestion management in restructured power system by rescheduling of generators using TLBO. In Electrical, Instrumentation and Communication Engineering (ICEICE), 2017 IEEE International Conference on (pp. 1-7). IEEE.

10. Phan, D.T. and Ghosh, S., 2016, July. Predicting and mitigating congestion for an electric power system under load and renewable uncertainty. In American Control Conference (ACC), 2016 (pp 6791-6796). IEEE.

11. Suganthi, S.T., Devaraj, D., HosiminThilagar, S. and Ramar, K., 2016, November. Improved multi objective differential evolution algorithm for congestion management in restructured power systems. In Industrial Electronics and Applications Conference (IEACon), 2016 IEEE (pp. 203-210). IEEE.

12. Trojan, P., Wolter, M. and Komarnicki, P., 2017, May. Agent based power system management-Concept of congestion management. In Electric Power Engineering (EPE), 2017 18th International Scientific Conference on (pp. 1-6). IEEE.

13. Shahgholian, G., Mahdavian, M., Janghorbani, M., Eshaghpour, I., \& Ganji, E. (2017, June). Analysis and simulation of UPFC in electrical power system for power flow control. In 2017 14th International Conference on Electrical Engineering/Electronics, Computer, Telecommunications and Information Technology (ECTI-CON) (pp 62-65). IEEE.

\section{AUTHORS PROFILE}

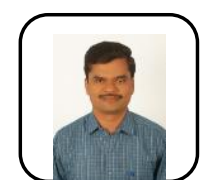

problems

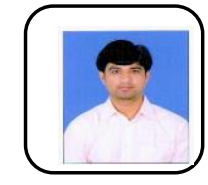

U. P. Kumar Chaturvedula, is designated as Associate Professor in the Department of Electrical and Electronics Engineering at Aditya College of Engineering Surampalem, A.P, India. His research areas include smart grids, power system optimization and electrical power distribution systems.

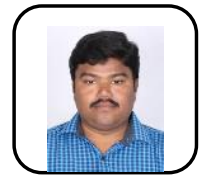

Dr. M. Ravindra, is an Assistant Professor in the Department of Electrical and Electronics Engineering at Aditya College of Engineering, ADB Road, Surampalem, A.P. India. His areas of interest include power system state estimation, power systems operation and control and electric power distribution systems. 